\title{
A Study of Influencing Factors of Satisfaction of Community Home-Based Nursing Service Based on ACSI Model
}

\author{
${ }^{I}$ School of Management, Harbin Normal University, Harbin, China \\ ${ }^{2}$ School of Management, Harbin Normal University, Harbin, China \\ *Corresponding authors. Email: 54051745@qq.com
}

Tianqi $\mathrm{Li}^{1}$, Lijun Wan ${ }^{2 * *}$

\begin{abstract}
Community home-based care service is the first choice for the elderly in China. Analysis of the factors affecting the satisfaction of the elderly is conducive to the improvement of the quality of service in the community in the future and the improvement of the elderly's happiness in their later life.In this paper, through on-the-spot visits, questionnaire survey method is used to investigate the elderly receiving community home-based elderly care services, and obtain data. Through data analysis, it is concluded that the key factor affecting the satisfaction of the elderly is the service quality of the service center.The innovation of this paper is to build the satisfaction model of community home-based elderly care based on the traditional ACSI model, and strive to maximize the happiness of the elderly by improving the role of key factors. Keywords: Community home-based nursing service, elderly, satisfaction, influencing factors, ACSI model
\end{abstract}

\section{INTRODUCTION}

According to national data released by the National Bureau of Statistics of China in late 2018, the number of elderly people aged 60 and over in China has reached 249.5 million, accounting for $17.9 \%$ of the total population ${ }^{[1]}$.During the " the 13th Five-year period" of the People's Republic of China, China's population aging trend still maintains a rising trend. China's future population aging situation is grim. It is evaluated that by 2020 , the number of elderly people over 60 years of age will increase to about 255 million $^{[2]}$.In the face of such a severe population aging, how to make the elderly live a happy and stable life in the later years is an inevitable job of the development of a well-off society in China. "The 13th Five Year National Aging Industry Development and Pension System Construction Plan" issued by the State Council of China, pointed out that it is an important measure to actively respond to the decision-making of population aging, and to ensure and improve People's livelihood, enhancing the happiness of the elderly and achieving a comprehensive well-off society have important strategic significance ${ }^{[2]}$.

Community home-based nursing is a form of retirement for the elderly who provide home care for the elderly, such as life care, domestic services, medical care, psychological comfort, etc ${ }^{[3]}$.Western developed countries are first facing the stage of population aging, so the research on the problem of providing for the aged and improving the satisfaction of the elderly is early. However, China's community home-based nursing service started late and developed slowly, and is still in the exploratory stage ${ }^{[4]}$.At the same time, it is more effective to combine the model with the analysis of influencing factors. Through building the construction of the community home-based nursing service quality model and through factor analysis, it is concluded that the service quality is positively related to the cleaning, food, medical and recreational services. Taking the classical model as a reference, the argumentation will have a foothold and thus be more persuasive. Thus,the scholar Xiong Wei based on the classic customer satisfaction model, the community home care service evaluation model was constructed innovatively. The study found that the community home care service perceived service quality, expected service quality and the image of community home care service and the community home care service satisfaction were significantly positive. ${ }^{[5]}$.Apply customer satisfaction theory and service quality theory, and then perform regression analysis on the data. Analysis of the factors affecting the satisfaction of community home care services from the basic situation of the elderly, the expectation of the elderly and the quality of service. It is concluded that we should enrich services according to the characteristics of the elderly, provide personalized services according to different expectations, and improve the quality of home-based pension services to improve the satisfaction of the elderly ${ }^{[6]}$. Some scholars argued that ACSI model is relatively perfect in China and has accumulated a lot of experience in different fields, which proves that the application of ACSI model is scientific and effective ${ }^{[7]}$.Through studied ACSI model and put forward that American customer satisfaction model is based on the consumption process of products or services. It has a complete system and good application effect. It is widely used in satisfaction evaluation ${ }^{[8]}$. 


\section{METHODS}

\subsection{Model Building and Variables Selection}

Using structural equation model to build a community home care service satisfaction model and then select variables.Structural equation model(SEM) has the advantage of being able to consider and process multiple dependent variables simultaneously[9],so it is suitable for analyzing the multivariable relationship of satisfaction.Structural equations can simultaneously process latent variables and their indicators [10].The model in this paper is based on multiple latent variables and observed variables, so the structural equation model is the best choice.

Draw on the traditional American Customer Satisfaction Index(ACSI) to build a community home care service satisfaction model, the initial model is shown in Figure 1. The community home care service satisfaction model consists of four variables: elderly satisfaction, elderly expectations,Community home nursing service value perception and Community home nursing service value perception. The variable settings in this article are shown in Table 1.

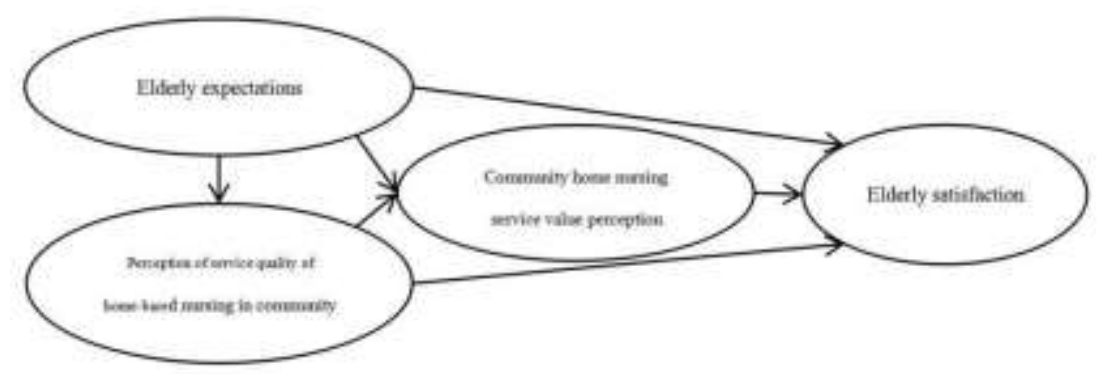

Figure 1 Initial model

Table 1 Variables

\begin{tabular}{|c|c|}
\hline Latent Variables & Manifest Variables \\
\hline \multirow[t]{2}{*}{$\begin{array}{l}\text { Elderly expectations } \\
\text { A }\end{array}$} & $\begin{array}{l}\text { Overall expectations for community home care services } \mathrm{X} 7 \\
\text { Expectations of meeting the physiological needs of home nursing service X8 } \\
\text { Expectations of meeting the psychological needs of home nursing service X9 }\end{array}$ \\
\hline & $\begin{array}{l}\text { Perception of the overall quality of community home care services X10 } \\
\text { Perception of the elderly day care service provided by the community X11 } \\
\text { Perception of community security services X12 } \\
\text { Perception of community health care services X13 } \\
\text { Perception of community canteen catering services X14 }\end{array}$ \\
\hline $\begin{array}{l}\text { Perception of } \\
\text { Service Quality of } \\
\text { Home-based Nursing } \\
\text { in Community } \\
\text { B }\end{array}$ & $\begin{array}{l}\text { Perception of intelligent retirement equipment provided by the community X15 } \\
\text { Perception of community greening environment and barrier-free access X16 } \\
\text { Perception of the quality of community service personnel X17 } \\
\text { Perception of the psychological comfort services provided by community X18 } \\
\text { Community provides entertainment venues and fitness equipment for the elderly X19 } \\
\text { Awareness of the community's ability to meet social needs X20 }\end{array}$ \\
\hline $\begin{array}{l}\text { Perception of Service } \\
\text { Value of Home-based } \\
\text { Nursing in Community } \\
\text { C }\end{array}$ & Relative to the price.Satisfaction degree of service quality obtained by the elderly X21 \\
\hline $\begin{array}{c}\text { Elderly Satisfaction } \\
\text { D }\end{array}$ & $\begin{array}{l}\text { Overall satisfaction of the elderly on community home nursing service X23 } \\
\text { Satisfaction with the needs of community home nursing services to meet physiological needs X24 } \\
\text { Satisfaction with the needs of community home nursing services to meet psychological needs X25 }\end{array}$ \\
\hline & $\begin{array}{l}\text { interviews with community leaders, staff and elderly } \\
\text { people who often receive community services. To ensure } \\
\text { the reasonableness of the content of the questionnaire. To } \\
\text { ensure the quality of the returned questionnaires. Relevant } \\
\text { options in the questionnaire were scored by Likert }\end{array}$ \\
\hline
\end{tabular}


5-subscale method, and 1-5 points were scored from low to high.

\section{RESULTS}

The data was analyzed by spss 20.0 software, and the reliability of the data was tested by Cronbach' $\alpha$ coefficient. The total Cronbach $\alpha$ coefficient was 0.941 , indicating that the data reliability was high. The KMO value of the sample was $0.938(>0.7)$, and the level of freedom reached 171 and the level of 0.000 reached a significant level, indicating that the data is suitable for factor analysis, as shown in Table 2.

Using AMOS24.0 to perform confirmatory factor analysis on the model, and based on the analysis results, the final model fitting results are shown in Table 3 . It shows that the SEM model of community home care service satisfaction has a good fit.

Table 2 Result of suitable

\begin{tabular}{|c|c|c|c|}
\hline $\mathrm{KMO}$ & \multicolumn{3}{|c|}{0.938} \\
\hline Bartlett's test of sphericity & \multicolumn{2}{|c|}{$\begin{array}{c}\text { Chi-squaredapproximation } \\
\text { df } \\
\text { Sig. }\end{array}$} & $\begin{array}{c}2787.102 \\
171 \\
0.000 \\
\end{array}$ \\
\hline Statistical test & Adaptation standard & Model parameters & Fit degree result \\
\hline$\chi^{2 / d f}$ & $<3$ & 1.826 & Fit \\
\hline RMSEA & $<0.08$ & 0.065 & Fit \\
\hline GFI & $>0.9$ & 0.877 & General fit \\
\hline AGFI & $>0.9$ & 0.838 & General fit \\
\hline NFI & $>0.9$ & 0.909 & Fit \\
\hline
\end{tabular}

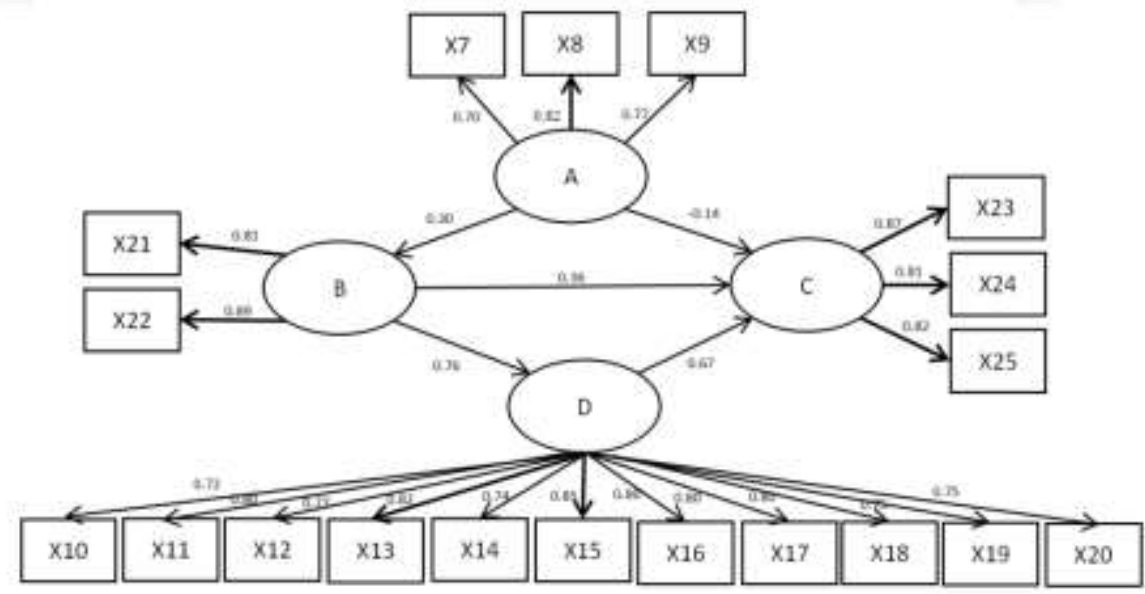

Figure 2 Modified normalized path analysis graph

(A refer to Elderly expectations; B refer to Perception of Service Quality of Home-based Nursing in Community; C refer to Perception of Service Value of Home-based Nursing in Community; D refer to Elderly Satisfaction.)

Next we conducted a critical path analysis.Using AMOS 24.0 to create a community home care service satisfaction path analysis diagram, as shown in Figure 2, the bold path is the critical path.

\section{DISCUSSION AND CONCLUSION}

Among the factors influencing the satisfaction of the elderly, the elderly have a significant positive correlation on the satisfaction of the quality of community home care services (the correlation coefficient is 0.67) is the key impact factor of the satisfaction of the elderly. Among the 
corresponding measurement variables, the intelligent old-age facilities have the greatest impact on the satisfaction of the elderly. The intelligent service can meet the diversified and personalized needs of the elderly, and has the characteristics of timeliness, convenience and efficiency. It is the development direction of the future community to improve service quality. At the same time, health care services, including the professional level of medical staff, medical equipment quality, basic medical items and other software and hardware conditions have a great impact on the satisfaction of the elderly. As the physical fitness of the elderly declines, the demand for health care services is increasing. Therefore, improving the level of community medical services, strengthening the professional quality of medical staff, and meeting the basic medical needs of the elderly are the key to improving the satisfaction of the elderly. From the analysis results, it can be seen that quality perception has a positive impact on value perception, which indirectly affects the satisfaction of the elderly.

The impact of value perception on the satisfaction of the elderly.Value perception has a direct positive impact on satisfaction. From the value perception factor, the elderly have a greater degree of perception of price-quality ratio and quality-price ratio, indicating that quality is the focus of the elderly compared with price, so the community should strive to improve the quality of service, thus ensuring high satisfaction with the elderly.Due to the decrease in the income of the elderly after retirement, or the lowering of the income level of the elderly due to physical health conditions, the daily life and medical expenses will increase. At this time, if the price of the community home care service is too high, it will directly affect the satisfaction of the elderly. Therefore, under the premise of ensuring good service quality, if the service price is also in line with the psychological expectations of the elderly, the satisfaction of the elderly will be higher.

The impact of old people's expectations on satisfaction. The expectation of the elderly is negatively correlated with satisfaction, but the impact is low. This may be related to the fact that the elderly have been living in the community for many years to understand the community, so the expectations of community service will change as the understanding increases. When experiencing service, the perceived difference between the quality of service and the expected quality of service is small, and the level of satisfaction is more due to service quality and service value. Moreover, related to the personality of the elderly group surveyed, most of the elderly are satisfied with the progress of the times, the improvement of living conditions, and the provision of old-age services. Even if there are any shortcomings, they are willing to be tolerant.

\section{ACKNOWLEDGEMENT}

This work was supported by Research on the sharing mechanism of intelligent community pension (Grants No. 18BGL260).

\section{REFERENCES}

[1] Ministry of Civil Affairs of the People's Republic of China. 2018 Statistical Report on Social Service Development.

[2] China Government Network.The State Council issued a notice on the development of the "13th Five-Year" national old age career development and pension system construction plan.Information on http://www.gov.cn/zhengce/content/2017-03/06/content _5173930.html.

[3] Gao Kaiying.Research on PPP Mode Applied to Chinese Community Home Care Service.Modern management science. (2015)84-86.

[4] Wang Jingjing, Ge Gaoqi,Guo Yitian, Zhang Xiumin. Current situation of community home care model at home and abroad. Chinese Journal of Gerontology (2017) 243-245.

[5] Xiong Wei.Research on Satisfaction Evaluation and Promotion Strategy of Community Home Care Service. Central China Normal University, (2017).

[6] Fei Yi.Research on Satisfaction of Home Care Service. Shanghai Jiaotong University, (2009).

[7] Wang Fei,Chi Mohan, Yue Fenglian,et al.Study on the construction of community health service resident satisfaction evaluation index system. Chinese General Practice,(2014)16-18.

[8] Chen Xi\& Li Bing.of ACSI Model in Customer Satisfaction Measurement. Science and Technology Innovation and Application, (2013)255.

[9] Hou Jietai,\&Wen Zhonglin\& Cheng Zijuan.Structural Equation Model and Its Application . Educational Science Press,2004.

[10] Wu Minglong.Structural Equation Model-AMOS operation and application.Chongqing University Press,2009. 